\title{
The health and development of children born to older mothers in the United Kingdom: observational study using longitudinal cohort data
}

\author{
(C) (1) OPEN ACCESS
}

\author{
Alastair G Sutcliffe reader in child health ${ }^{1}$, Jacqueline Barnes professor of psychology ${ }^{2}$, Jay Belsky \\ professor of human development ${ }^{23}$, Julian Gardiner senior researcher in statistics ${ }^{2}$, Edward Melhuish \\ professor of human development ${ }^{2}$
}

${ }^{1}$ Institute of Child Health, University College London, UK; ${ }^{2}$ Institute for the Study of Children, Families and Social Issues, Birkbeck, University of London, London WC1E 7HX, UK ; ${ }^{3}$ University of California, Davis, CA, USA

\begin{abstract}
Objective To assess relations between children's health and development and maternal age.

Design Observational study of longitudinal cohorts.

Setting Millennium Cohort Study (a random sample of UK children) and the National Evaluation of Sure Start study (a random sample of children in deprived areas in England), 2001 to 2007.
\end{abstract}

Participants 31257 children at age 9 months, 24781 children at age 3 years, and 22504 at age 5 years.

Main outcome measures Childhood unintentional injuries and hospital admissions (aged 9 months, 3 years, and 5 years), immunisations (aged 9 months and 3 years), body mass index, language development, and difficulties with social development (aged 3 and 5 years).

Results Associations were independent of personal and family characteristics and parity. The risk of children having unintentional injuries requiring medical attention or being admitted to hospital both declined with increasing maternal age. For example, at three years the risk of unintentional injuries declined from $36.6 \%$ for mothers aged 20 to $28.6 \%$ for mothers aged 40 and hospital admissions declined, respectively, from $27.1 \%$ to $21.6 \%$. Immunisation rates at nine months increased with maternal age from $94.6 \%$ for mothers aged 20 to $98.1 \%$ for mothers aged 40 . At three years, immunisation rates reached a maximum, at $81.3 \%$ for mothers aged 27 , being lower for younger and older mothers. This was linked to rates for the combined measles, mumps, and rubella immunisation because excluding these resulted in no significant relation with maternal age. An increase in overweight children at ages 3 and 5 years associated with increasing maternal age was eliminated once maternal body mass index was included as a covariate. Language development was associated with improvements with increasing maternal age, with scores for children of mothers aged 20 being lower than those of children of mothers aged 40 by 0.21 to 0.22 standard deviations at ages 3 and 4 years. There were fewer social and emotional difficulties associated with increasing maternal age. Children of teenage mothers had more difficulties than children of mothers aged 40 (difference 0.28 SD at age 3 and 0.16 SD at age 5).

Conclusion Increasing maternal age was associated with improved health and development for children up to 5 years of age.

\section{Introduction}

In developed countries the trend towards later childbearing has been strong. ${ }^{1-3}$ In England and Wales the number of births to women aged 40 or more trebled from 1989 to 2009, when it reached 26976 births. ${ }^{4}$ Similar patterns exist in almost all developed countries. In New Zealand, for example, the rate of births to women aged 35 or more almost doubled between 1995 and 2010. Similarly, in the United States between 1990 and 2004 birth rates increased by $43 \%$ in women aged $35-39$, by $62 \%$ in women aged $40-44$, and by more than $150 \%$ in women aged $45 .{ }^{6}$ Established risks associated with older maternal age include preterm labour, fetal malformation, fetal death, and increased risk of maternal cardiometabolic disease. ${ }^{3}$ Given the substantial and rapid increase in older motherhood and the known medical risks, it is important to determine whether, and how, older motherhood is linked to child health and development beyond the fetal stage. Although research documenting the deleterious consequences of young motherhood on children's development is substantial, ${ }^{7-11}$ evidence of any effects, deleterious or beneficial, of older motherhood on offspring is lacking, ${ }^{1}$ perhaps owing to the recency of the trend in delayed childbearing.

The few studies on the effects of older parenthood on offspring reported mixed results. In an investigation of maternal age and extremely low birth weight live births ( $\mathrm{n}=14671$ children), infants born to mothers aged 40 or older were $22 \%$ more likely to survive and had a $13 \%$ decreased risk of neurodevelopmental 
impairment or death compared with those of mothers aged less than $20 .{ }^{3}$ In another study ( $\mathrm{n}=33437$ children), advanced paternal age predicted increased externalising behaviour (that is, aggression, disobedience) and poorer cognitive ability, whereas the opposite was true of advanced maternal age. ${ }^{12}$ Advanced paternal and maternal age predicted poorer social functioning among Israeli male adolescents $(n=403486),{ }^{13}$ and schizophrenia and autistic behaviours were more common among the children of older fathers and mothers. ${ }^{14}{ }^{15}$ As there is little evidence that evaluates relations between older motherhood and children's health and development beyond birth and the postnatal period, we tested hypotheses that maternal age would show relations with children's health and development independent of personal and background characteristics.

\section{Methods}

The study sample consisted of children aged 9 months, 3 years, and 5 years from the Millennium Cohort Study ${ }^{16}$ and from the National Evaluation of Sure Start study. ${ }^{17}$ Eligible children for the Millennium Cohort Study were all children in England born over a period of 16 months from September 2000 and living in the 398 wards. The random sample was clustered geographically by electoral ward with some oversampling to ensure adequate representation of wards with a high number of ethnic minority populations ( $\geq 30 \%$ black or Asian populations in 1991 census), and disadvantaged areas from the poorest $25 \%$ of wards based on the child poverty index, ${ }^{18}$ which is based on the proportion of children in families receiving means tested benefits. Overall there were 188 advantaged wards (not in poorest 25\%), 191 disadvantaged wards, and 19 wards with a high proportion of ethnic minority families. Children were sampled from the government's child benefit records. Child benefit is a universal provision, payable to mothers from the birth of their children. The take-up of child benefit exceeds 97\%. Apart from the possibility of eligible families being too rich or too ill informed to claim, most of the children not claimed for were ineligible as the children of non-nationals with temporary or unconfirmed residence status, such as foreign armed forces, overseas students, and recent immigrants, including asylum seekers. The attained sample at nine months was 18552 children and families (response rate $70 \%$ ). Of these, 14898 (80.3\% retention rate) were seen again when the children were aged 3 and 14678 ( $79.1 \%$ retention rate) when the children were aged 5. Additional children and families were recruited at three years to give 15 590 at age 3 and 15246 at age $5 .^{19}$

The sample from the National Evaluation of Sure Start study was selected from areas in England chosen to receive a Sure Start local programme, all in the $20 \%$ most disadvantaged areas defined by the child poverty index - that is, all were from disadvantaged areas. ${ }^{18}$ From children born in 200 randomly chosen Sure Start areas during 29 months from January 2002, we chose a random sample of 12705 infants aged 9 months (response rate $84.0 \%$ ), again using the child benefit records as a sampling frame. Of those seen at this age, 11118 children and families were randomly selected to be followed-up when the child was aged 3 years, 9191 (82.7\%) of whom participated in data collection at the 3 years age point. When the children were aged 5 years we randomly selected to be followed-up 8000 of the children and families seen when the children were aged 3; data were collected from 7258 (response rate $90.7 \%$ ). We applied no exclusion criteria except to include in analyses only the first born child when multiple births occurred. The total sample consisted of 31257 infants aged 9 months (18 552 from the Millennium Cohort Study and 12705 from the National
Evaluation of Sure Start), 247813 year olds (15 590 from the Millennium Cohort Study and 9191 from the National Evaluation of Sure Start), and 225045 year olds (15 246 from the Millennium Cohort Study and 7258 from the National Evaluation of Sure Start study). In both studies we included all mothers and children. The age range of mothers was between 13 and 57 years.

\section{Outcomes}

We chose the child outcomes because they have been used as indicators of child wellbeing in reports from the World Health Organization, ${ }^{20}$ applied to the total population, were likely to predict later health and development, and were reliably measured by parental report or researcher. Outcomes collected by parental report were social difficulties experienced by the children, using the strengths and difficulties questionnaire ${ }^{21}$; unintentional injuries requiring medical treatment (from nurse, general practitioner, hospital, or medical clinic) in the past year; admissions to hospital in the past year; and receipt of all recommended immunisations since the previous interview. The recommended immunisations (all free under the National Health Service) in terms of the age points in the studies were: three doses of vaccines against diphtheria, tetanus, pertussis, polio, and haemophilus influenzae type b (hib) at 9 months of age, and by 3 years of age boosters for diphtheria, tetanus, pertussis, and polio and vaccinations against measles, mumps, and rubella (typically delivered as a combined vaccine), hepatitis B, meningitis $\mathrm{C}$, and pneumococcal infection. An additional immunisation outcome was included at three years, defined as complete immunisations, excluding combined measles, mumps, and rubella. Data on uptake of immunisations were obtained only from the Millennium Cohort Study. To calculate the children's body mass index a researcher measured their weight and height at ages 3 and 5 during home visits. Data on the unintentional injury and hospital admission outcomes were available at all three ages. In addition, researchers assessed language development at ages 3 and 5 using the British ability scales naming vocabulary subscale. ${ }^{22}$

We coordinated data collection across both studies, with researchers trained in common and similar procedures used to ensure collection of comparable information so that data could be combined across the studies. At each age point the parents were interviewed at home and the children measured. Personal and background information collected by parental report served as control variables in analyses.

\section{Statistical analysis}

We analysed three continuous outcomes in the children: body mass index (range 6.7-63.6), naming vocabulary score (range 20-80, higher being better) from the British ability scales, ${ }^{22}$ and social difficulties score (range $0-34$, lower being better) from the strengths and difficulties questionnaire. ${ }^{21}$ The four binary outcomes chosen were unintentional injury since the last survey, admission to hospital since the last survey, in receipt of all recommended immunisations, and overweight. We defined being overweight using reference data on body mass index from the US Centers for Disease Control and Prevention ${ }^{23}$ as being above the 85 th percentile for the children's sex and age. To model the continuous variables we used linear terms in the regression models.

Since both samples were geographically clustered we used linear mixed effects models for the continuous outcomes and logistic regression mixed effects models for the binary outcomes, with a random effect fitted for clustering in all models. The principal 
independent variable was maternal age at the children's birth, treated as a continuous variable.

Regression models were fitted with the following covariates: children's sex, children's age, number of siblings, parity, birth weight, breast fed for at least six weeks, ethnic group, raised by single parent, paternal age, raised in workless household, family income, mother's educational attainment, and mother's social class (defined by regular occupation). Paternal age was grouped into 10 bands of about equal size: $(<22.5$ years, 22.5 to $<25,25$ to $<27,27$ to $<29,29$ to $<31,31$ to $<33,33$ to $<35,35$ to $<37.5$. 37.5 to 40 , and $>40$ ); we included the father being absent as an additional category. We selected the covariates a priori to avoid any confounding of maternal age effects on outcomes. Models of the children's body mass index and overweight were also controlled for mother's body mass index. The covariates did not show high colinearity; only maternal and paternal age (0.66) and worklessness and income (0.57) were above 0.5 .

Depending on the outcome, between $78.7 \%$ and $93.7 \%$ of children had complete data on all variables. For most variables less than $10 \%$ of data was missing, with $10 \%$ exceeded only by mother's body mass index (nine months, three years, and five years), paternal age (five years), child's body mass index, overweight, naming vocabulary, and social difficulties score (three years). The greatest amount of missing data was for social difficulties score at three years, at $22.8 \%$. We used the Amelia II package to impute missing data, ${ }^{24}$ with all covariate and outcome variables used in the imputations. Five imputations were generated and models fitted to each imputed dataset. Model results were consolidated using Rubin's rules, ${ }^{25}$ with degrees of freedom ascertained using Hesterberg, ${ }^{26}$ equation 24.

We selected a linear or polynomial model for maternal age. To achieve this we fitted an initial linear model then added higher order terms successively until the highest order term was no longer statistically significant, at which point we adopted the previous model as the final one. The final adjusted models were linear or quadratic for maternal age. To investigate possible confounding between maternal age and first time motherhood, we fitted additional models that included an interaction between first time motherhood and maternal age. No such interactions were significant and are not discussed further.

Models were fitted in R 2.11.1. We used the linear mixed effects procedure to fit the linear mixed effects models and the generalised linear mixed models penalised quasilikelihood procedure ${ }^{27}$ to fit the logistic regression mixed effects models. We undertook analyses for the Millennium Cohort Study and the National Evaluation of Sure Start samples separately and for the combined total sample. As results were broadly similar in all cases, we present the results for the combined sample.

\section{Results \\ Models}

Table $1 \Downarrow$ shows the characteristics of the sample, table $2 \Downarrow$ the raw outcome data tabulated by maternal age categories, and table $3 \Downarrow$ the results of the final adjusted and unadjusted models . The figure $\Downarrow$ shows the results of the adjusted models for outcomes showing statistically significant relations with maternal age.

\section{Unintentional injuries}

The risk of unintentional injuries declined with increasing maternal age, with the final models for children aged 9 months, 3 years, and 5 years being linear, quadratic, and linear, respectively (figure).
At nine months the risk of unintentional injuries declined across maternal age, with the risk in children of mothers aged 20 being $9.5 \%$, decreasing to $6.1 \%$ for mothers aged 40 . The model is quadratic for 3 year olds, showing a decline from $36.6 \%$ for mothers aged 20 to $28.6 \%$ for mothers aged 40.5 (where the curve reaches a minimum). The model is linear for 5 year olds, with risk decreasing from $29.1 \%$ for mothers aged 20 to $24.9 \%$ for mothers aged 40.

\section{Admissions to hospital}

The risk of children being admitted to hospital also declined with increasing maternal age, with the final models being linear in all cases (figure).

At nine month, the probability of children being admitted to hospital declined from $16.0 \%$ when mothers were aged 20 to $10.7 \%$ when mothers were aged 40 . For 3 year olds, the probability declined from $27.1 \%$ when mothers were aged 20 to $21.6 \%$ when mothers were 40 . For 5 year olds, the change in hospital admissions with increasing maternal age was not statistically significant.

\section{Immunisations}

The final models of complete immunisation rates by maternal age for 9 month olds and 3 year olds were quadratic (figure).

At nine months the rate of complete immunisation increased with maternal age, from $94.6 \%$ when mothers were aged 20 to $98.1 \%$ when mothers were 40 . At three years the maximum rate of complete immunisations was $81.3 \%$ when mothers were aged 27.3, with lower rates among younger and older mothers. Complete immunisations at three years, excluding combined measles, mumps, and rubella immunisation were also considered; the final model was linear, with no significant relation between immunisation rate and maternal age, indicating that non-linear effects are linked to take-up of the combined measles, mumps, and rubella immunisation.

\section{Children's body mass index and overweight}

Initial models showed a significant positive association between the children's body mass index and maternal age. However, once maternal body mass index was controlled for, no significant association with maternal age was found for either children's body mass index or children's overweight (table 2).

\section{Language development (British ability scales naming vocabulary)}

The final models of naming vocabulary score in relation to maternal age were quadratic, with scores increasing as maternal age increased (figure). At three years, the score for children of mothers aged 20 was 0.22 standard deviations below that for the children of mothers aged 40. At five years, the value for children of mothers aged 20 was 0.21 standard deviations below that for the children of mothers aged 40 .

\section{Social and emotional difficulties}

The final models for the strengths and difficulties total problem score in relation to maternal age were quadratic at three years and linear at five years, with scores decreasing as maternal age increased, indicating better social development (figure). At three years, the score for children of mothers aged 20 was 0.28 standard deviations higher than for children of mothers aged 40 , and at five years, the corresponding difference was 0.16 standard deviations. 


\section{Discussion}

Increasing maternal age was associated with children having fewer hospital admissions and unintentional injuries, a greater likelihood of having had all of their immunisations by 9 months of age, better language, and fewer social and emotional difficulties. Such findings contrast with the known obstetric risks associated with older motherhood ${ }^{1-3}$ and serve as a counterpoint to evidence highlighting poorer health and developmental outcomes for children of younger mothers $(<20$ years). ${ }^{7-11}$ The positive findings in relation to increasing maternal age were generally consistent with the few other studies on children of older mothers, often defined as 40 years or older, which focused on other issues such as neurodevelopment, educational achievement, substance misuse, and juvenile crime ${ }^{12}$ rather than, as here, general health and development, both cognitive-linguistic and socio-emotional. There are, however, exceptions in the literature to the conclusion that older motherhood carries few risks for child functioning. One study of Israeli male adolescents showed poorer social and emotional functioning in association with both teenage mothers and mothers aged 40 or older at their child's birth (relative to other mothers). ${ }^{13}$ Older mothers tend to be better educated, have higher family income, and be married, all factors associated with greater child wellbeing. ${ }^{72}$ Analyses controlled for these and other personal factors. Hence the results are indicative of associations with maternal age rather than covarying characteristics, or at least those included in this research. Also noteworthy in this study was the inclusion of children living in deprived neighbourhoods and experiencing high levels of family deprivation, as well as children representative of the general population, to increase the likelihood of identifying any adverse impacts. The fact that results were broadly similar for all outcomes when the analyses were undertaken separately for the population representative Millennium Cohort Study sample and the deprived National Evaluation of Sure Start sample indicates that these results are likely to be applicable across the spectrum of deprivation.

The only health related outcome revealing any adverse relation with childbearing in older age was immunisation uptake by age 3 years, which declined with maternal age after age 33 . This could have been a historical artifact, related to parental anxiety regarding now discredited claims linking the combined measles, mumps, and rubella with autism, ${ }^{29}$ which were prevalent in the media around the time of the birth and early years of the children studied here. It is possible that older mothers were more influenced by the media reports. Further analyses of immunisations excluding the combined measles, mumps, and rubella immunisation supported this interpretation as they revealed no relations between maternal age and uptake of all other immunisations.

The likelihood of a child being overweight increased with increasing maternal age, but not when maternal body mass index was controlled for, indicating that this result was explained by greater maternal body mass index in older mothers, rather than by maternal age in itself. Nevertheless, this association is one that should be of concern for health practitioners.

\section{Strengths and limitations of the study}

This study has all the limitations of observational studies in attributing causality but does provide evidence relevant to an important clinical topic. Also, all covariates and some child outcomes apart from the children's weight and height and naming vocabulary measurements were based on parental report; the fact that the data were collected in an optimal manner by direct parental interview with highly trained interviewers would seem to obviate somewhat the limitation. Although some child health information could have been extracted from medical records, that method also has pitfalls for data completeness and comparability. Error in measurement is always possible, but the measures taken were the best available and we have no reason to assume systematic mis-measurement, and if measurement error is not systematically related to a variable then measurement error decreases the likelihood of significant results. Inevitably some attrition occurred as the children aged and families withdrew or became non-contactable, but the attrition rates compare favourably with other longitudinal studies. Also, analyses were carried out in two ways, using only complete cases and using multiple imputation to include the full sample to deal with this issue. These two sets of analyses did not differ substantially. The initial hypotheses were tentative for the direction of effects owing to limited published evidence on the health of children born to older mothers. Finally, there was a shortfall in information on paternal age, as a significant proportion of children were living separately from their father. None the less, the large dataset, the representativeness of the samples, the powerful nature of the children's outcomes, and the fact that data were collected originally for a different purpose improved the likelihood of the findings being valid. Also the fact that results were similar for all outcomes for separate analyses of the population representative Millennium Cohort Study sample and the deprived National Evaluation of Sure Start sample indicates that these results are likely to be applicable to the whole population and across the spectrum of deprivation.

\section{Conclusion}

In contrast with the obstetric risks known to be associated with older motherhood these results indicate that increasing maternal age was associated with children having fewer hospital admissions and unintentional injuries, a greater likelihood of better protection from ill health through completed immunisations by age 9 months, better language development, and fewer social and emotional difficulties. The findings are noteworthy given the continuing increase in mean age of childbearing. It will be important to continue to examine relations between child outcomes and maternal age to see if the situation changes as the children age, and to explore possible mediating and moderating factors for the relations associated with maternal age. Possible mechanisms for the observed relations between child outcomes and maternal age might be environmental, such as differences in parenting, or genetic, as found for paternal age where the longer fathers and grandfathers waited to have children, the more likely it was for their offspring to live longer and healthier lives. This seemed to be due to longer telomeres of older fathers' sperm, related to increased longevity and development, being inherited by offspring. ${ }^{30}$ Further research should explore possible mechanisms. Finally, the results of this study are relevant to concerns raised about older people seeking to use fertility treatments and possible risks posed to children delivered by older mothers. ${ }^{31}$

We thank the families and their children for their cooperation throughout both projects.

Contributors: All authors helped to plan the research, and took part in the writing of the final article. JG undertook the statistical analyses, supervised by EM. EM had full access to all the data in the study and takes complete responsibility for the integrity of the data and the accuracy of the data analysis. 


\section{What is already known on this topic}

Established risks associated with older maternal age ( $\geq 40$ years) include preterm labour, fetal malformation, fetal death, and increased risk of maternal cardiometabolic disease

Evidence related to child health and development beyond the immediate postnatal period is lacking for the children of older mothers

There is an increased risk of deleterious consequences for children's health and development associated with young motherhood

\section{What this study adds}

Increasing maternal age was associated with several beneficial effects on children

Children had fewer hospital admissions and unintentional injuries, a greater likelihood of being fully immunised by age 9 months, better language, and fewer social and emotional difficulties

Funding: This research was funded by the Wellcome Trust through a grant entitled "Health of children born to older mothers"; the funding body had no involvement in the design and conduct of the study; collection, management, analysis, and interpretation of the data; and preparation, review, or approval of the manuscript. All authors are independent of the funding agency.

Competing interests: All authors have completed the ICMJE uniform disclosure form at www.icmje.org/coi_disclosure.pdf (available on request from the corresponding author) and declare: no support from any organisation for the submitted work; no financial relationships with any organisations that might have an interest in the submitted work in the previous three years; and no other relationships or activities that could appear to have influenced the submitted work.

Ethical approval: This study was approved for both studies by the National Health Service South West multicentre research ethics committee (reference No MREC/01/6/65). Participants in both studies gave written informed consent.

Data sharing: The data from the Millennium Cohort Study and the National Evaluation of Sure Start study are available from the Economic and Social Data Service (www.esds.ac.uk/).

1 Sutcliffe A, Baki Y. What is known about children born to older parents? In: Bewley S, Ledger W, Nikolaou D, eds. Reproductive ageing. Royal College of Obstetricians and Gynaecologists Press, 2009:173-82.

2 Berryman J, Thorpe K, Windridge K. Older mothers: conception, pregnancy and birth after 35. Pandora, 1995.

3 Vohr BR, Tyson JE, Wright LL, Perritt, RL, Li L, Poole WK. Maternal age, multiple birth, and extremely low birth weight infants. J Pediatr 2009;154:498-503.

4 Office for National Statistics. Birth statistics. Series FM1 No 35. ONS, 2007.

5 Statistics New Zealand.Births and deaths: year ended March 2011. 2012. www.stats.govt. nz/browse_for_stats/population/births/BirthsAndDeaths_HOTPYeMar11.aspx.

6 Martin JA, Hamilton BE, Sutton PD, Ventura SJ, Menacker F, Kirmeyer S, Division of Vital Statistics. Births: final data for 2004 . National Vital Statistics Reports 55(1). US Department of Health and Human Services, Centers for Disease Control and Prevention, 2004.

7 Moffitt TE, E-Risk Study Team. Teen-aged mothers in contemporary Britain. J Child Psychol Psych 2002;43:727-42.

8 Botting B, Rosato M, Wood R. Teenage mothers and the health of their children. Popul Trends 1998;93:19-27.

9 Fraser AM, Brockert JE, Ward RH. Association of young maternal age with adverse reproductive outcomes. New Engl J Med 1995;332:1113-7.

10 Gilbert W, Jandial D, Field N, Bigelow P, Danielsen B. Birthoutcomes in teenage pregnancies. J Matern Fetal Neonatal Med 2004;16:265-70.

11 Phipps MG, Blume JD, Demonner SM. Young maternal age associated with increased risk of postnatal death. Obstet Gynaecol 2002;100:481-6.

12 Fergusson DM, Woodward LJ. Maternal age and educational and psychosocial outcomes in early adulthood. J Child Psychol Psych 1999;40:479-89.
13 Weiser M, Reichenberg A, Werbeloff N, Kleinhaus K, Lubin G, Shmushkevitch M, et al. Advanced parental age at birth is associated with poorer social functioning in adolescent males: shedding light on a core symptom of schizophrenia and autism. Schizophr Bull 2008;34:1042-6.

14 Zammit S, Allebeck P, Dalman C, Lundberg I, Hemmingson T, Owen MJ, et al. Paternal age and risk for schizophrenia. Br J Psychiatry 2003;183:405-8.

15 Croen LA, Najjar DV, Fireman B, Grether JK. Maternal and paternal age and risk of autism spectrum disorders. Arch Pediatr Adolesc Med 2007;161:334-40.

16 Dex S, Joshi H. Millennium cohort study, first survey: a user's guide to initial findings Centre for Longitudinal Studies, University of London Institute of Education, 2004.

17 Melhuish E, Belsky J, Leyland AH, Barnes J, National evaluation of Sure Start team. Effects of fully-established Sure Start local programmes on 3-year-old children and their families living in England: a quasi-experimental observational study. Lancet 2008:372:1641-7.

18 Noble M, Smith G, Penhale B, Wright G, Dibben C, Owen T, et al. Measuring multiple deprivation at the small area level: the indices of deprivation 2000. Regeneration research summary No 37. Department of the Environment, Transport and the Regions, 2000.

19 Plewis I. Millennium cohort study first survey: technical report on sampling. 4th ed. Centre for Longitudinal Studies, University of London Institute of Education, 2007.

20 Irwin LG, Siddiqi A, Hertzman C. Early child development: a powerful equalizer. Final report for the World Health Organization's Commission on the Social Determinants of Health. WHO, 2007. 2011. http://whqlibdoc.who.int/hq/2007/a91213.pdf.

21 Goodman R. The strengths and difficulties questionnaire: a research note. J Child Psychol Psychiatry 1997;38:581-6.

22 Elliott CD, Smith P, McCulloch K. British ability scales . 2nd ed. NFER-Nelson, 1996.

23 Centers for Disease Control and Prevention. Percentile data files with LMS values. CDC, 2010.

24 Honaker J, King G, Blackwell M. Amelia II (R package) 2010. http://cran.r-project.org/web/ packages/Amelia/index.html.

25 Rubin DB. Multiple imputation for nonresponse in surveys . Wiley, 1987.

26 Hesterberg T. Combining multiple imputation t, chi-square, and F inferences. Research report No 75. MathSoft, 1998.

27 Venables WN, Ripley BD. MASS (R package). http://cran.rproject.org/web/packages/ MASS/index.html.

28 Kiernan KE, Mensah FK. Maternal indicators in pregnancy and children's infancy that signal future outcomes for children's development, behaviour and health: evidence from the Millennium Cohort Study. University of York, 2009.

29 Centers for Disease Control and Prevention. Measles, mumps, and rubella (MMR) vaccine and autism fact sheet. CDC, 2007.

30 Eisenberg DTA, Hayes MG, Kuzawa CW. Delayed paternal age of reproduction in humans is associated with longer telomeres across two generations of descendants. Proc Natl Acad Sci USA 2012: published online 11 June.

31 Caplan AL, Patrizio P. Are you ever too old to have a baby? The ethical challenges of older women using infertility services. Semin Reprod Med 2010;28:281-6.

Accepted: 11 July 2012

\section{Cite this as: BMJ 2012;345:e5116}

This is an open-access article distributed under the terms of the Creative Commons Attribution Non-commercial License, which permits use, distribution, and reproduction in any medium, provided the original work is properly cited, the use is non commercial and is otherwise in compliance with the license. See: http://creativecommons.org/licenses/by$\mathrm{nc} / 2.0 /$ and http://creativecommons.org/licenses/by-nc/2.0/legalcode. 


\section{Tables}

Table 1| Descriptive statistics of participants. Values are numbers (percentages) unless stated otherwise

\begin{tabular}{|c|c|c|c|}
\hline \multirow[b]{2}{*}{ Variables } & \multicolumn{3}{|c|}{ Children's age } \\
\hline & 9 months & 3 years & 5 years \\
\hline No of participants & 31257 & 24781 & 22504 \\
\hline Child had unintentional injury in past year & $2669(8.5)$ & $8069(32.8)$ & $6216(27.8)$ \\
\hline Child was admitted to hospital in past year & $4583(14.7)$ & $6153(26.0)$ & $3295(14.7)$ \\
\hline Child was completely immunisation & $17553(96.0)$ & $18537(75.2)$ & - \\
\hline Child is overweight & - & $6832(32.7)$ & $6531(30.0)$ \\
\hline Male sex & $16012(51.2)$ & $12364(51.0)$ & $11437(50.8)$ \\
\hline Child was breast fed for at least six weeks & $12413(39.9)$ & $10248(41.4)$ & $9470(42.1)$ \\
\hline Mother is single parent & 7457 (23.9) & $5490(22.2)$ & $4689(20.8)$ \\
\hline Child is in workless household & 8709 (27.9) & $5992(24.2)$ & $4648(20.7)$ \\
\hline \multicolumn{4}{|l|}{ Child's ethnicity: } \\
\hline White & $24882(79.6)$ & $19857(81.3)$ & $18176(81.8)$ \\
\hline Mixed & $1235(4.0)$ & $891(3.6)$ & $771(3.5)$ \\
\hline Indian & $634(2.0)$ & $505(2.1)$ & $466(2.1)$ \\
\hline Pakistani/Bangladeshi & $2393(7.7)$ & $1740(7.1)$ & $1573(7.1)$ \\
\hline Black & $1396(4.5)$ & $927(3.8)$ & $812(3.7)$ \\
\hline Other & $700(2.2)$ & $494(2.0)$ & $433(1.9)$ \\
\hline \multicolumn{4}{|l|}{ Mother's parity: } \\
\hline 1 & $11913(47.3)$ & $11654(47.0)$ & $10710(47.6)$ \\
\hline 2 & $8173(32.4)$ & $8044(32.5)$ & $7290(32.4)$ \\
\hline$\geq 3$ & $5107(20.3)$ & $5083(20.5)$ & $4504(20.0)$ \\
\hline \multicolumn{4}{|l|}{ No of siblings of child: } \\
\hline 0 & $13044(41.7)$ & $6218(25.1)$ & $3714(16.6)$ \\
\hline 1 & $10387(33.2)$ & $10703(43.2)$ & $10118(45.1)$ \\
\hline 2 & $4894(15.7)$ & $4829(19.5)$ & $5379(24.0)$ \\
\hline$\geq 3$ & $2932(9.4)$ & $3010(12.2)$ & $3227(14.4)$ \\
\hline \multicolumn{4}{|l|}{ Mother's highest qualification: } \\
\hline None & $5050(16.2)$ & 3407 (13.8) & $2827(12.6)$ \\
\hline GCSE or equivalent & $12683(40.6)$ & $10143(41.0)$ & $9500(42.3)$ \\
\hline A level or equivalent & $7273(23.3)$ & $6022(24.4)$ & $5456(24.3)$ \\
\hline Degree or higher degree & $5092(16.3)$ & $4272(17.3)$ & $3957(17.6)$ \\
\hline Other qualification & $1112(3.6)$ & $877(3.5)$ & $717(3.2)$ \\
\hline \multicolumn{4}{|l|}{ Mother's socioeconomic status*: } \\
\hline Management and professional & $6720(22.4)$ & $6113(25.8)$ & $4933(22.7)$ \\
\hline Intermediate & $4986(16.6)$ & $3668(15.5)$ & $4929(22.7)$ \\
\hline Small employer or self employed & $1107(3.7)$ & $1559(6.6)$ & $1808(8.3)$ \\
\hline Low supervision and technical & $1808(6.0)$ & $1630(6.9)$ & $2106(9.7)$ \\
\hline Semi-routine and routine & $13233(44.0)$ & $9353(39.5)$ & $7071(32.6)$ \\
\hline Unemployed & $2212(7.4)$ & $1376(5.8)$ & $839(3.9)$ \\
\hline \multicolumn{4}{|l|}{ Household income per year (£): } \\
\hline$<11000$ & $11629(39.2)$ & $5941(24.6)$ & $4459(20.0)$ \\
\hline $11000-22000$ & $11423(38.5)$ & $8641(35.8)$ & $7273(32.4)$ \\
\hline$>22000$ & $6594(22.2)$ & $9536(39.5)$ & $10612(47.6)$ \\
\hline Mean (SD) child's age (years) & $0.795(0.0574)$ & $3.16(0.192)$ & $5.21(0.251)$ \\
\hline Mean (SD) birth weight (g) & $3310(598)$ & 3330 (594) & $3330(593)$ \\
\hline
\end{tabular}


Table 1 (continued)

\begin{tabular}{lccc} 
& \multicolumn{3}{c}{ Children's age } \\
\cline { 2 - 4 } Variables & $\mathbf{9}$ months & $\mathbf{3}$ years & $\mathbf{5}$ years \\
Mother & $27.9(6.09)$ & $28.3(6.07)$ & $28.4(6.01)$ \\
\hline Father & $32.1(6.47)$ & $32.3(6.40)$ & $32.4(6.35)$ \\
\hline Mean (SD) mother's body mass index prepregnancy & $24.2(4.92)$ & $24.4(4.99)$ & $24.3(4.94)$ \\
\hline Mean (SD) child's BAS naming vocabulary score & - & $48.1(11.6)$ & $52.0(11.5)$ \\
\hline Mean (SD) child's SDQ difficulties score & - & $11.1(5.11)$ & $9.1(4.87)$ \\
\hline BAS=British ability scales; SDQ=strengths and difficulties questionnaire. & & \\
*Defined by usual employment. & & & \\
\hline
\end{tabular}




\begin{tabular}{|c|c|c|c|c|c|}
\hline \multirow[b]{2}{*}{ Child outcomes by age } & \multicolumn{5}{|c|}{ Maternal age band } \\
\hline & $<22$ & $22-<26$ & $26-<30$ & 30-33 & $>33$ \\
\hline \multicolumn{6}{|l|}{ Unintentional injury: } \\
\hline 9 months & $730(11.7)$ & $525(9.0)$ & $549(8.0)$ & $389(7.3)$ & $476(6.8)$ \\
\hline 3 years & $1752(38.9)$ & 1459 (33.5) & $1811(33.4)$ & $1331(30.7)$ & $1685(28.8)$ \\
\hline 5 years & $1186(30.7)$ & $1155(29.7)$ & $1437(28.4)$ & $1043(25.7)$ & $1381(25.3)$ \\
\hline \multicolumn{6}{|l|}{ Admitted to hospital: } \\
\hline 9 months & $1172(18.8)$ & $946(16.2)$ & $947(13.9)$ & $655(12.3)$ & $859(12.3)$ \\
\hline 3 years & $1449(33.8)$ & $1177(28.5)$ & $1348(25.6)$ & $964(23.0)$ & $1186(20.8)$ \\
\hline 5 years & $676(17.4)$ & $643(16.4)$ & $714(14.1)$ & $534(13.1)$ & 724 (13.2) \\
\hline \multicolumn{6}{|l|}{ Completely immunised: } \\
\hline 9 months & $2744(93.5)$ & 2816 (95.3) & $4093(96.6)$ & $3382(96.9)$ & $4500(96.8)$ \\
\hline 3 years & $1521(65.1)$ & $1580(66.9)$ & $2361(65.8)$ & $2004(65.4)$ & $2687(64.2)$ \\
\hline 3 years (excluding MMR) & $1623(69.4)$ & $1677(71.0)$ & 2509 (69.9) & $2150(70.1)$ & $2956(70.6)$ \\
\hline \multicolumn{6}{|l|}{ Overweight: } \\
\hline 3 years & $1232(32.6)$ & $1143(31.7)$ & $1525(32.4)$ & $1231(32.9)$ & $1679(33.6)$ \\
\hline 5 years & $1167(31.2)$ & $1131(29.8)$ & $1464(29.6)$ & $1182(29.8)$ & $1576(29.7)$ \\
\hline \multicolumn{6}{|l|}{ Mean (SD) body mass index: } \\
\hline 3 years & $16.8(2.24)$ & $16.7(2.02)$ & $16.7(2.06)$ & $16.8(2.02)$ & $16.8(2.25)$ \\
\hline 5 years & $16.3(1.89)$ & $16.3(2.04)$ & $16.3(1.88)$ & $16.3(1.86)$ & $16.3(1.94)$ \\
\hline \multicolumn{6}{|c|}{ Mean (SD) BAS naming vocabulary score: } \\
\hline 3 years & $45.3(10.4)$ & $46.1(11.3)$ & $48.4(11.9)$ & $49.8(11.6)$ & $50.0(11.5)$ \\
\hline 5 years & $49.0(10.5)$ & $49.5(11.3)$ & $52.2(11.5)$ & $53.9(11.5)$ & $54.1(11.6)$ \\
\hline \multicolumn{6}{|c|}{ Mean (SD) SDQ strengths and difficulties score: } \\
\hline 3 years & $33.3(5.26)$ & $32.2(5.24)$ & $31.0(4.95)$ & $30.2(4.66)$ & $29.7(4.70)$ \\
\hline 5 years & $30.7(5.23)$ & $29.9(4.99)$ & $29.0(4.76)$ & $28.4(4.42)$ & $28.1(4.53)$ \\
\hline
\end{tabular}

$\mathrm{MMR}=$ measles, mumps, and rubella immunisation; $\mathrm{BAS}=\mathrm{British}$ ability scales; $\mathrm{SDQ}=$ strengths and difficulties questionnaire.

Maternal age bands approximate the fifths of maternal age distribution. 


\begin{tabular}{|c|c|c|c|}
\hline \multicolumn{4}{|c|}{ Table $3 \mid$ Results from final models } \\
\hline Child outcomes by age & Coefficient $^{*}$ & Coefficient $(95 \% \mathrm{Cl})$ & $P$ value \\
\hline \multicolumn{4}{|l|}{ Unintentional injury: } \\
\hline 9 months & Age & $-0.12(-0.17$ to -0.068$)$ & $<10^{-4}$ \\
\hline \multirow[t]{2}{*}{3 years } & Age & $-0.092(-0.13$ to -0.058$)$ & $<10^{-4}$ \\
\hline & $\mathrm{Age}^{2}$ & $0.022(0.0038$ to 0.040$)$ & 0.018 \\
\hline 5 years & Age & $-0.054(-0.089$ to -0.019$)$ & 0.0026 \\
\hline \multicolumn{4}{|l|}{ Admitted to hospital: } \\
\hline 9 months & Age & $-0.12(-0.15$ to -0.077$)$ & $<10^{-4}$ \\
\hline 3 years & Age & $-0.074(-0.11$ to -0.037$)$ & 0.0001 \\
\hline 5 years & Age & $-0.031(-0.075$ to 0.013$)$ & 0.17 \\
\hline \multicolumn{4}{|l|}{ Completely immunised: } \\
\hline \multirow[t]{2}{*}{9 months } & Age & 0.27 (0.18 to 0.37$)$ & $<10^{-4}$ \\
\hline & $\mathrm{Age}^{2}$ & $-0.070(-0.12$ to -0.024$)$ & 0.0031 \\
\hline \multirow[t]{2}{*}{3 years } & Age & $-0.034(-0.074$ to 0.0058$)$ & 0.094 \\
\hline & $\mathrm{Age}^{2}$ & $-0.032(-0.053$ to -0.011$)$ & 0.0033 \\
\hline 3 years (excluding MMR) & Age & $0.013(-0.034$ to 0.061$)$ & 0.58 \\
\hline \multicolumn{4}{|l|}{ Body mass index: } \\
\hline 3 years & Age & $0.018(-0.013$ to 0.050$)$ & 0.25 \\
\hline 5 years & Age & $0.015(-0.014$ to 0.044$)$ & 0.31 \\
\hline \multicolumn{4}{|l|}{ Overweight: } \\
\hline 3 years & Age & $0.013(-0.02$ to 0.047$)$ & 0.44 \\
\hline 5 years & Age & $0.012(-0.023$ to 0.047$)$ & 0.50 \\
\hline \multicolumn{4}{|c|}{ BAS naming vocabulary score: } \\
\hline \multirow[t]{2}{*}{3 years } & Age & 0.63 (0.44 to 0.82$)$ & $<10^{-4}$ \\
\hline & $\mathrm{Age}^{2}$ & $-0.12(-0.21$ to -0.038$)$ & 0.0053 \\
\hline \multirow[t]{2}{*}{5 years } & Age & 0.59 (0.44 to 0.75$)$ & $<10^{-4}$ \\
\hline & $\mathrm{Age}^{2}$ & $-0.13(-0.22$ to -0.044$)$ & 0.0032 \\
\hline \multicolumn{4}{|c|}{ SDQ strengths and difficulties score: } \\
\hline \multirow[t]{2}{*}{3 years } & Age & $-0.35(-0.43$ to -0.28$)$ & $<10^{-4}$ \\
\hline & $\mathrm{Age}^{2}$ & $0.088(0.047$ to 0.13$)$ & $<10^{-4}$ \\
\hline 5 years & Age & $-0.20(-0.27$ to -0.12$)$ & $<10^{-4}$ \\
\hline
\end{tabular}

$M M R=m e a s l e s$, mumps, and rubella immunisation; $B A S=B r i t i s h$ ability scales; $S D Q=$ strengths and difficulties questionnaire.

Curvilinear models are parameterised so that the coefficient for age is the model slope at maternal age 30 .

${ }^{*}$ Coefficients are per five years of maternal age. 


\section{Figure}
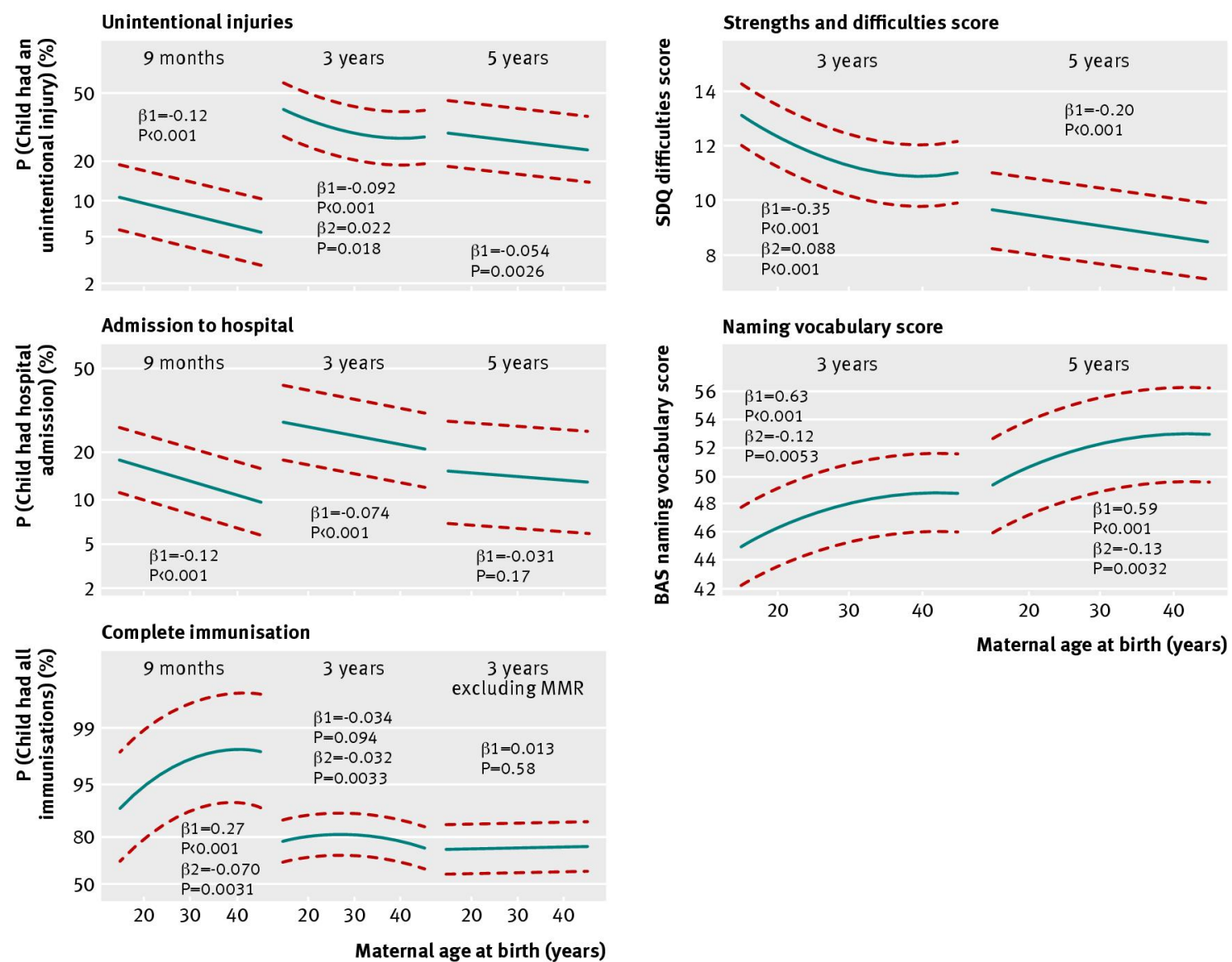

Adjusted models showing regression lines with $95 \%$ confidence intervals for outcomes by maternal age. Unintentional injury in children (quadratic model, 3 years), admission to hospital (linear models), complete immunisation (quadratic models, 9 months and 3 years), British ability scales naming vocabulary score (quadratic models), and total score on strengths and difficulties questionnaire (quadratic model, 3 years). Model coefficients, per 5 years of maternal age, are given with $P$ values. Quadratic models are parameterised so that the coefficient for the linear component of maternal age $(\beta 1)$ gives the model slope at maternal age 30 . MMR=measles, mumps, and rubella immunisation; BAS=British ability scales 